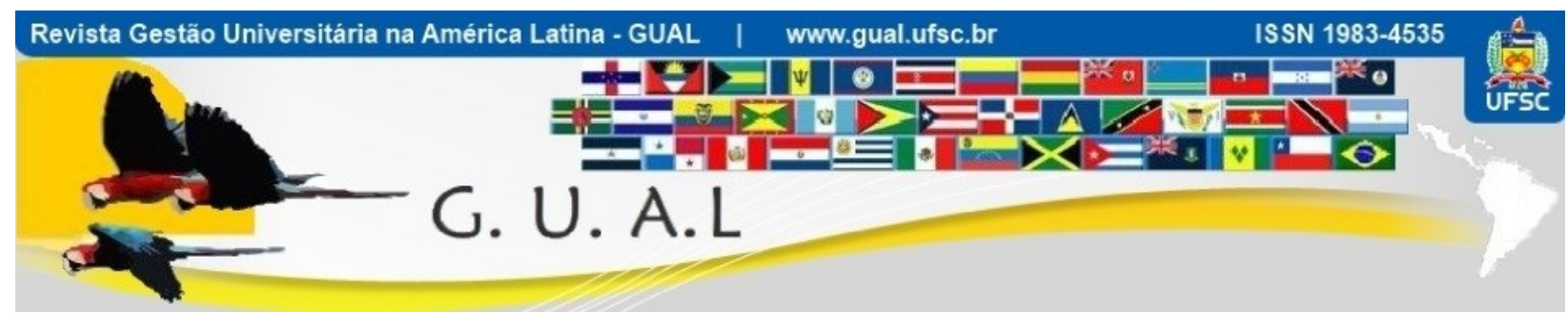

DOI: http://dx.doi.org/10.5007/1983-4535.2019v12n2p183

\title{
PERFIL E PERSPECTIVAS DOS EGRESSOS DO CURSO DE ADMINISTRAÇÃO DA UFFS: UM ESTUDO REALIZADO NO CAMPUS CHAPECÓ/SC
}

\author{
PROFILE AND PERSPECTIVES OF GRADUATES OF THE UFFS \\ ADMINISTRATION COURSE: A STUDY CARRIED OUT ON CAMPUS \\ CHAPECÓ/SC
}

\author{
Camila Giacomin, Bacharel \\ http://orcid.org/0000-0002-3181-1055 \\ camila.giacomin@extremecode.com.br \\ Universidade Federal da Fronteira Sul | Campus Chapecó \\ Chapecó | Santa Catarina | Brasil \\ Lilian Wrzesinski Simon, Mestra \\ http://orcid.org/0000-0003-0307-4948 \\ lilian.uffs@gmail.com \\ Universidade Federal da Fronteira Sul | Campus Chapecó \\ Chapecó | Santa Catarina | Brasil \\ Kelly Cristina Benetti Tonani Tosta, Doutora \\ http://orcid.org/0000-0003-0531-5282 \\ kellycbenetti@gmail.com \\ Universidade Federal da Fronteira Sul | Campus Chapecó \\ Chapecó | Santa Catarina | Brasil
}

Recebido em 12/junho/2018

Aprovado em 24/dezembro/2018

Publicado em 02/maio/2019

Sistema de Avaliação: Double Blind Review

Esta obra está sob uma Licença Creative Commons Atribuição-Uso. 


\title{
RESUMO
}

Este artigo tem como objetivo analisar o perfil e as perspectivas dos egressos do curso de administração da UFFS - Campus Chapecó/SC e sua contribuição para a avaliação do curso e da universidade. A pesquisa contou com a participação de 70 dos 84 egressos diplomados pelo curso de administração desde a sua implantação. Foram coletadas informações sobre o perfil pessoal, educacional e profissional dos participantes, acerca de seus objetivos relacionados à continuidade dos estudos e inerentes ao campo profissional. As opiniões dos egressos acerca dos componentes relacionados ao curso e à universidade, bem como o impacto da formação recebida na vida destes administradores foram determinantes para a avaliação de aspectos importantes da gestão do curso e do campus, contribuindo para a proposição de melhorias para o curso e para a universidade. Os principais aspectos apontados pelos egressos que carecem de atenção pela coordenação do curso e pela gestão do campus estão relacionados ao campo profissional. Esta percepção ficou evidente na avaliação dos componentes do curso, na contribuição do curso e da universidade para o desenvolvimento do egresso, bem como na avaliação das competências/habilidades adquiridas pelos egressos com a formação recebida.

Palavras-chave: Avaliação de Cursos. Egressos. Gestão Universitária.

\begin{abstract}
This article aims to analyze the profile and prospects of the graduates of the administration course of UFFS - Campus Chapecó/SC, as well as their contribution to the evaluation of the course and university. The survey was attended by 70 of the 84 graduates graduating from the management course since its implantation. Information on the personal, educational and professional profile of the participants was collected, about their objectives related to the continuity of the studies and the professional field. The opinions of the graduates about the components related to the course and the university, as well as the impact of the training received in the lives of these administrators were decisive for the evaluation of important aspects of the management of the course and of the campus, contributing For the proposition of improvements to the course and to the university. The main aspects pointed out by the graduates who lack attention for the coordination of the course and the management of the campus is related to the professional field. This perception was evident in the evaluation of the components of the course, in the contribution of the course and the University for the development of the egress, as well as in the evaluation of the skills/skills acquired by the graduates with the formation received.
\end{abstract}

Keywords: Evaluation of courses. Graduates. University management. 


\section{INTRODUÇÃO}

As transformações ocorridas nas últimas décadas com a transposição da era industrial para a era da informação e do conhecimento, aliadas a quebra das barreiras econômicas gerada pela globalização, acirraram a competitividade do mercado e intensificaram os problemas sociais. A criatividade para superar os desafios impostos às organizações e à sociedade neste contexto perpassa pela educação e capacitação, mediante o desenvolvimento de competências pessoais e profissionais.

O sucesso ou insucesso dos negócios das organizações está atrelado à qualidade da administração. Para uma organização ser bem-sucedida ela precisa de bons administradores, com potencial para extrair os melhores resultados, valorizar o capital intelectual e preparar a empresa para a mudança, procurando adaptá-la a um ambiente cada vez mais dinâmico (SOBRAL; PECI, 2008).

O administrador qualificado apresenta-se como um diferencial competitivo, pois está preparado para exercer funções nas mais diversas áreas da organização e dispõe de competências essenciais para exercer cargos de gestão. Além disso, o profissional formado em administração precisa ser comprometido com as causas da sociedade, uma vez que a administração e o empenho grupal são condições indispensáveis para o cumprimento das metas e responsabilidades sociais (KOONTZ; ODONNELL; 1981).

O curso de administração da Universidade Federal da Fronteira Sul (UFFS) busca formar administradores não apenas dotados de competências técnicas, mas com uma visão humanista, que detenham capacidade para gerir organizações formais e aplicar seus conhecimentos para além delas, atuando como agentes de desenvolvimento e transformação social na Mesorregião da Fronteira Sul, onde o ensino superior foi uma conquista resultante de um processo de luta e organização da sociedade (SIMON et al, 2016; UFFS, 2017).

Com o intuito de conhecer o perfil e o percurso dos egressos após a formação no ensino superior, o presente estudo tem como objetivo analisar o perfil e as perspectivas dos egressos do curso de administração da UFFS - Campus Chapecó/SC e sua contribuição para a avaliação do curso e da universidade.

O conhecimento do perfil e das perspectivas dos egressos é essencial para avaliar o atendimento das expectativas deles e da própria universidade com relação ao curso, além do que permite o estabelecimento de ações voltadas ao relacionamento mútuo. Ao valorizar as aspirações dos egressos, conhecer melhor sua vida, seus valores, seu modo de pensar e agir, a 
coordenação do curso de Administração da UFFS pode investir na aproximação entre profissionais e acadêmicos para a troca de conhecimentos e experiências.

Para a melhor compreensão desse fenômeno, este artigo destaca temas como: a formação do administrador, com vistas ao espaço acadêmico e profissional; o papel da universidade na formação do administrador, englobando a avaliação do curso de administração, e; as políticas de acompanhamento de egressos. Na sequência é apresentada a metodologia adotada na pesquisa, seguida por uma breve caracterização do curso de administração da UFFS e o perfil esperado do egresso. Os resultados da pesquisa de campo demonstram o perfil do egresso do curso e as suas perspectivas com relação à continuidade dos estudos, ao campo profissional e a avaliação do curso e da universidade.

\section{A FORMAÇÃO DO ADMINISTRADOR}

A administração é praticada há mais de dois mil anos, desde os primórdios da vida humana. Com o passar do tempo se expandiu da atividade fabril para as empresas industriais e gradualmente passou a abranger todas as organizações. Contudo, a administração realmente se consolidou a partir das teorias preconizadas com o surgimento da Escola da Administração Científica. Tais teorias são de extrema valia como base dos princípios para o estudo da administração enquanto ciência e na prática profissional. (LACOMBE; HEILBORN, 2003).

A formação do Administrador no Brasil se desenvolveu concomitantemente com o processo de industrialização, a partir da década de 30, mas começou a ganhar contornos mais claros na década de 40. O curso de administração teve início no limiar da década de 50, movido pela necessidade latente de mão de obra qualificada e, consequentemente, a profissionalização do ensino da administração (CFA, 2016).

O Conselho Federal de Administração (CFA) preconiza que a concretização da formação do administrador como agente de mudanças, no curso de administração, foi oficializada por meio da Lei $\mathrm{n}^{\mathrm{o}} 4.769$, de 09 de setembro de 1965, que regulamenta também a profissão de Administrador. Com a aprovação desta Lei, o acesso ao mercado profissional deveria ser privativo aos portadores de títulos expedidos pelo sistema universitário.

Mas, na prática isso nem sempre acontece. A concepção de Maximiano (2009) acerca do termo administrador serve para explicar essa realidade. Para o autor, administradores são todos os indivíduos que administram qualquer conjunto de recursos. Assim, quase todas as pessoas, independentemente da posição que ocupam, ou do título de seus cargos, 
desempenham tarefas de administração. Quem quer que esteja manejando recursos ou tomando decisões está administrando. O processo de administrar é importante em qualquer escala de utilização de recursos: pessoal, familiar, organizacional e social.

Não obstante, no campo profissional, a profissionalização do trabalho do administrador é a garantia de que os resultados venham a ser alcançados efetivamente, apresentando lucratividade ao empregador e benefícios para a sociedade. "Espera-se que o administrador tenha como principal qualidade a iniciativa para conseguir soluções para as dificuldades encontradas e para colocá-las em ação" (LACOMBE; HEILBORN, 2003, p. 7). Essa condição requer um nível de capacitação satisfatório que não pode ser adquirido sem a apropriação de técnicas administrativas adequadas, geralmente veiculadas pelo ensino da ciência da administração.

Além da evolução do ensino da ciência administrativa no espaço acadêmico, gerado pela regulamentação da profissão, ele também ocorre através da "expansão comercial e quando as exigências de caráter administrativo se fazem presentes, ocasionando a necessidade de se organizar o ensino comercial" no espaço corporativo (PINTO; MOTTER JUNIOR, 2012, p. 5).

Enfim, o ensino da administração busca formar profissionais providos de uma visão sistêmica dos principais enfoques para a gestão das organizações e têm por meta buscar o sucesso das empresas oferecendo o conhecimento dos principais métodos e instrumentos que possibilitem os melhores resultados na gestão financeira, de mercado, de pessoas e clientes, entre outros (MURINI; FREO; MADRUGA, 2006).

O trabalho do profissional da Administração, portanto, não pode mais ser pensado a partir de perspectiva da tarefa, de um determinado posto de trabalho, mas de um conjunto de ocupações consolidadas a partir de um grupo de competências e habilidades, construído a partir da articulação dos vários saberes oriundos de múltiplos espaços, ou seja, da escola, das empresas e do círculo de suas diversas relações sociais.

\subsection{O PAPEL DA UNIVERSIDADE NA FORMAÇÃO DO ADMINISTRADOR}

Considerando que as universidades são a principal instituição responsável pela formação dos administradores, elas precisam atender aos critérios estabelecidos pelo Ministério da Educação (MEC) no tocante à estruturação do Projeto Pedagógico do Curso (PPC) e suas diretrizes curriculares, respeitando na sua elaboração uma série de "conteúdos 
que revelem inter-relações com a realidade nacional e internacional, segundo uma perspectiva histórica e contextualizada de sua aplicabilidade no âmbito das organizações e do meio através da utilização de tecnologias inovadoras" (CNE, 2004, s.p.).

De acordo com a regulamentação do Conselho Nacional de Educação (CNE), a formação do administrador está atrelada a uma série de parâmetros voltados a uma formação ampla, dotada de competências e habilidades que o capacitem para a tomada de decisão tanto preventiva como reativa, reconhecendo problemas, equacionando soluções, promovendo a comunicação, desenvolvendo o pensamento crítico, e exercendo a racionalidade, a criatividade, a troca de conhecimentos e experiências, entre outras, de acordo com o contexto em que irá atuar.

Ao formar-se em uma universidade o administrador precisa ir além da utilização das ferramentas de gestão que lhe são apresentadas, ele precisa estar apto a desenvolver novas estratégias, inovando e melhorando seu campo de atuação profisssional. A evolução da ciência da administração depende da capacidade de ação destes profissionais, seja pelo desenvolvimento da pesquisa acadêmica ou pela sua prática profissional no mercado de trabalho.

O graduado em Administração deve apresentar um perfil genérico conforme as especificidades relacionadas: internalização de valores de responsabilidade social, justiça e ética profissional; sólida formação humanística e visão global que o habilite a compreender o meio social, político, econômico e cultural onde está inserido e a tomar decisões em um mundo diversificado e interdependente; sólida formação técnica e científica para atuar na administração das organizações, além de desenvolver atividades específicas da prática profissional; competência para empreender, analisando criticamente as organizações, antecipando e promovendo suas transformações; capacidade de compreensão da necessidade do contínuo aperfeiçoamento profissional e do desenvolvimento da autoconfiança (MEC, 1999).

\subsubsection{A avaliação do curso de Administração}

Assim como os demais cursos de graduação, o curso de administração é avaliado periodicamente pelo Instituto Nacional de Estudos e Pesquisas Educacionais Anísio Teixeira (INEP), observando as diretrizes propostas pelo Sistema Nacional de Avaliação da Educação Superior (SINAES). De acordo com o INEP (2015b, p. 13): 
As avaliações indicam [...] a presença dos indicadores de qualidade que consolidam o PPC, a infraestrutura e o corpo docente dos cursos, identificando aspectos inovadores que vão além do projeto original, reforçam a identidade das IES e dos cursos, sinalizam atualização ante as inovações educacionais, tecnológicas e culturais e possibilitam o realinhamento permanente do planejamento institucional.

Entre os indicadores utilizados para avaliação da qualidade de um curso está o perfil profissional dos egressos. Os critérios de análise utilizados buscam dimensionar o nível de expressão das competências do egresso em seu perfil profissional (INEP, 2015a).

A inserção produtiva dos egressos é um dos aspectos respeitáveis da cidadania, o reconhecimento do valor dessa premissa tem crescido nos últimos anos, simultaneamente à evolução tecnológica e ao duplo processo de integração e da concorrência. É preciso formar cidadãos capazes de desempenhar atividades que sequer existem atualmente, isso sugere ensinar conteúdos e habilidades úteis no presente, mas também ensinar a compreender o futuro, fora das instituições formais (MEHEDFF, 1999).

Consequentemente, é primordial que as IES incluam em seus currículos ajustes, com o objetivo de assegurar aos profissionais, formados por ela, conhecimentos, habilidades e atitudes para desempenharem atividades e funções em uma abrangente série de processos, capazes de resolver dificuldades inerentes à sua área de formação e superar imprevistos (LOUSADA; MARTINS, 2005).

Frente ao exposto, é importante que as universidades estabeleçam políticas de acompanhamento de egressos capazes de mensurar o perfil de seus ex-alunos e o conhecimento dos níveis de inserção no mercado de trabalho e da evolução profissional dos seus diplomados.

\subsubsection{A participação do egresso na avaliação}

Ainda que haja o afastamento entre ex-aluno e universidade, o vínculo entre estes, por mais fraco que seja, permanece ao longo da vida e jamais se rompe (CABRAL, 2017). Entretanto, na maioria das universidades públicas brasileiras essa percepção ainda não extrapola os limites da retórica, ou seja, daquele vínculo de portador de um diploma da IES onde se estudou por vários anos e da qual se guarda lembranças marcantes.

O relacionamento como os egressos está sendo construído ou retomado lentamente nestas instituições, sendo poucas aquelas que exploram efetivamente essa prática. Isso pode ser justificado pelo fato do relacionamento com os egressos constar no núcleo de temas 
optativos, entre os indicadores de avaliação do SINAES e não ser compreendido para além desta perspectiva (LOUSADA; MARTINS, 2005; QUEIROZ, 2014).

Entretanto, o acompanhamento de egressos é uma fonte de informações para a gestão universitária, servindo como indicador de avaliação no âmbito dos cursos oferecidos e em nível institucional (LOUSADA; MARTINS, 2005; MIRANDA; PAZELLO; LIMA, 2015). Um acompanhamento de egressos eficaz figura como diferencial competitivo para a IES, tanto para melhorar os seus índices avaliativos, uma de suas preocupações recorrentes, como para fornecer subsídios que permitam ao curso potencializar a formação de seus alunos (TEIXEIRA; MACCARI, 2014).

Silva e Bezerra (2015 p. 2) acreditam que "o egresso poderá trazer contribuições valiosas para a instituição, possibilitando uma visão de aspectos relevantes de procedimentos de avaliação e de processos educativos, evidenciando as demandas da sociedade pela sua percepção". Assim sendo, as IES precisam envolvê-los e instigá-los a participar, expressando sua opinião acerca dos mais diversos assuntos que lhe cabem, entre eles a sua inserção e atuação profissional.

Os autores defendem que as avaliações dos egressos possibilitam "a identificação das exigências constantes do mercado de trabalho e os consequentes ajustes nas propostas político-pedagógicas, numa busca frenética pela melhor qualificação e formação acadêmica" (SILVA; BEZERRA, 2015 p. 14). Portanto, uma política de acompanhamento dos egressos consistente deve posicionar o profissional formado no mercado de trabalho, promover a educação continuada e auxiliar as coordenações de cursos e outros departamentos com informações repassadas pelos egressos.

\section{METODOLOGIA}

Essa pesquisa tem como finalidade analisar o perfil e as perspectivas dos egressos do curso de administração da UFFS, considerando as especificidades do Campus Chapecó/SC. A abordagem da pesquisa tem um enfoque predominantemente quantitativo (ZANELLA, 2006), uma vez que traduziu as informações e percepções dos egressos em números para em seguida analisá-las descritivamente.

Quanto aos fins, é classificada como descritiva e aplicada (GERHARDT; SILVEIRA 2009; GIL, 2010), pois ao relacionar as opiniões do egresso pode fornecer informações úteis 
para o desenvolvimento de ações de melhoria do curso de administração e da integração dos acadêmicos com os profissionais da administração diplomados pela UFFS.

Quanto aos meios, configura-se como uma pesquisa de campo, bibliográfica, documental e estudo de caso (YIN, 2001; MARCONI; LAKATOS, 2010). Na pesquisa de campo foram coletados, junto aos egressos, os dados primários necessários ao estudo. As fontes bibliográficas e documentais, ou seja, os dados secundários formam o substrato para a análise dos dados primários (MARCONI; LAKATOS, 2010). Como a pesquisa ocorreu em uma unidade específica, e seus resultados são aplicáveis à realidade em questão ela apresentase como um estudo de caso único (YIN, 2001).

O universo de análise compreendeu todos os egressos do curso de Administração do Campus Chapecó da UFFS, desde o momento em se formou a primeira turma, no ano de 2014, até o final do ano de 2016, ou seja, a última turma que concluiu o curso e colou grau até a realização da coleta dos dados da pesquisa.

O instrumento de coleta de dados utilizado para obtenção das informações foi um questionário estruturado com perguntas fechadas (VERGARA, 2009) onde os participantes puderam se manifestar de acordo com uma série de alternativas pré-definidas.

Da população de 85 egressos do curso, foram obtidas 70 participações de ex-alunos que aderiram ao convite e responderam ao questionário formatado na plataforma de formulários on line do Google e enviado por e-mail ou via rede social entre os dias 8 e 22 de maio de 2017, o que corresponde a uma amostra representativa de $82,35 \%$ da população total. Acerca desta amostra vale ressaltar que é incomum obter um percentual tão elevado de respostas em pesquisas realizadas com egressos, dada a dificuldade de acesso a este público, pelo fato de haver o desligamento da instituição no momento da formatura, bem como pela fragilidade das políticas de acompanhamento de egressos adotadas nas IES brasileiras (LOUSADA; MARTINS, 2005; QUEIROZ, 2014; SILVA; BEZERRA, 2015).

A análise e interpretação das informações obtidas, por meio dos questionários, são apresentadas em forma de gráficos, tabelas e descrições. A análise foi conduzida com a adoção do método estatístico (SILVESTRE, 2007) que permitiu a codificação dos dados de uma distribuição usando medidas de frequência, com números absolutos, dados proporcionais e a atribuição de pesos em escalas que variam entre (-2) e (3) para a avaliação de aspectos relativos ao curso e a universidade, sendo o indicador um considerado como ponto neutro na análise e o indicador zero desconsiderado devido à dificuldade de atribuição de peso/valor. 
Considerando o número de participantes, foi possível criar uma escala de variação proporcional às respostas obtidas na pesquisa de campo, com índices que variam entre (-140) para o extremo negativo e 210 pontos para o extremo positivo, sendo considerado o intervalo entre os indicadores um e 70 como ponto neutro na escala para alguns aspectos avaliados.

O método de calculo adotado na tabulação e análise dos dados foi a multiplicação entre o número de respondentes e o peso (positivo ou negativo) atribuído a cada resposta. Com base nos resultados da pesquisa de campo foi possível avaliar o perfil e as perspectivas dos egressos que possibilitam propor ações para a melhoria do curso de administração da UFFS.

\section{O CURSO DE ADMINISTRAÇÃO DA UFFS NA ÓTICA DOS EGRESSOS}

O curso de Graduação em Administração da UFFS tem como objetivo formar administradores com conhecimentos, habilidades e atitudes para gerenciar e liderar todos os tipos de empreendimentos quer sejam empresas, organizações ou projetos, planejando, controlando, organizando e dirigindo essas atividades. Um profissional dotado de capacidade analítica e empreendedora, com visão sistêmica de organizações, para constituir-se em agente de mudança e transformação social, tendo em vista a responsabilidade e ética coletiva, presente e futura, comprometido ainda com os processos de cooperação voltados para o desenvolvimento econômico regional integrado e sustentado (UFFS, 2017).

As habilidades e competências que o aluno precisa desenvolver no decorrer do curso acompanham as diretrizes curriculares nacionais propostas pelo CNE para o curso de Administração e o perfil que se espera do egresso da UFFS caracteriza-se pela qualificação para atuar na gestão de organizações diversas, com uma formação técnico-científica e empreendedora e multidisciplinar, que lhe permita desenvolver senso crítico e visão abrangente dos negócios que a ele compete dirigir e gerenciar (UFFS, 2017).

\subsection{PERFIL E PERSPECTIVAS DOS EGRESSOS DO CURSO DE ADMINISTRAÇÃO DA UFFS}

A pesquisa realizada junto aos egressos do curso de administração do campus Chapecó-SC demonstrou uma série de características que podem ser exploradas pela coordenação do curso tanto para criar políticas de relacionamento com este público, bem como para avaliar e até melhorar alguns aspectos relacionados ao curso, caso seja necessário. 
Os dados levantados através da aplicação do questionário mostraram que a maioria dos diplomados em administração pela UFFS possui entre 20 e 40 anos, sendo que apenas dois respondentes informaram ter idade superior a 40 anos. Há, portanto, uma predominância de jovens, pois $82,86 \%$ dos egressos possuem menos de 30 anos. Observa-se que $50 \%$ dos participantes da pesquisa estão na faixa etária entre 20 e 24 anos, contemplando 35 egressos. Isso significa que a metade dos estudantes que ingressaram no curso o fez em até dois anos após a conclusão do ensino médio. Entre os demais, 23 egressos possuem entre 25 e 29 anos, ou seja, 32,9\% dos egressos ingressaram na UFFS algum tempo depois de terem concluído o ensino médio, caso o tenham realizado em idade regular, seguido de sete egressos que possuem entre e 30 a 34 anos, o que corresponde a 10\% dos respondentes. Uma minoria de $4,3 \%$ (três egressos) se enquadra na faixa de 35 a 39 anos e apenas $2,9 \%$ estão na faixa acima de 40 anos de idade.

Quanto ao gênero, 47 egressos são mulheres, que corresponde a 67,1\% dos respondentes, e 23 egressos são do gênero masculino, contemplando 32,9\% dos participantes.

A adesão feminina ao ensino superior é uma tendência recorrente nas universidades brasileiras, mas é uma realidade recente. Além disso, os motivos que as levam a buscar o ensino superior refletem a desigualdades de gênero e a dificuldade de ingresso no mercado de trabalho, que as leva a se sujeitar à realização de atividades precárias. As questões relacionadas à raça também seguem na mesma perspectiva (BARRETO, 2014).

Apesar da política de ingresso de graduação da UFFS contemplar a reserva de vagas prioritárias para estudantes autodeclarados negros e pardos, além de vagas suplementares para indígenas (UFFS, 2017), no que tange à raça, 62 egressos são brancos, perfazendo uma proporção de $88,6 \%$ da amostra, ao passo que oito se autodeclararam pardos $(11,4 \%$ dos participantes), não havendo nenhuma outra raça autodeclarada. Não foram investigados os dados relacionados à evasão para justificar esses dados, contudo, a política de gestão da diversidade na UFFS está avançando no decorrer dos anos, com vistas à inclusão e à permanência das minorias sociais desfavorecidas pela sociedade no ensino superior. Estudos com egressos de turmas posteriores se fazem importantes para constatar os seus resultados.

Acerca do estado civil, os dados demonstram que 48 egressos $(68,6 \%)$ se declararam solteiros, oito são casados (11,4\%), 14 (20\%) vivem em união estável, não houve nenhum egresso separado ou divorciado. Acredita-se que a possibilidade de ingressar na universidade tenha influenciado nos objetivos pessoais relacionados ao casamento, uma vez que os jovens 
das camadas populares costumam estabelecer suas prioridades de acordo com as oportunidades que dispõe, buscando conciliar questões pessoais, acadêmicas e profissionais.

No que se refere ao aspecto acadêmico observa-se que durante o período em que permaneceram no campus os egressos realizaram diversos tipos de atividades extracurriculares, alguns se dedicando a mais de uma no decorrer do curso. As principais atividades desenvolvidas pelos egressos são apresentadas no gráfico 1:

Gráfico 1 Atividades extracurriculares realizadas pelos egressos

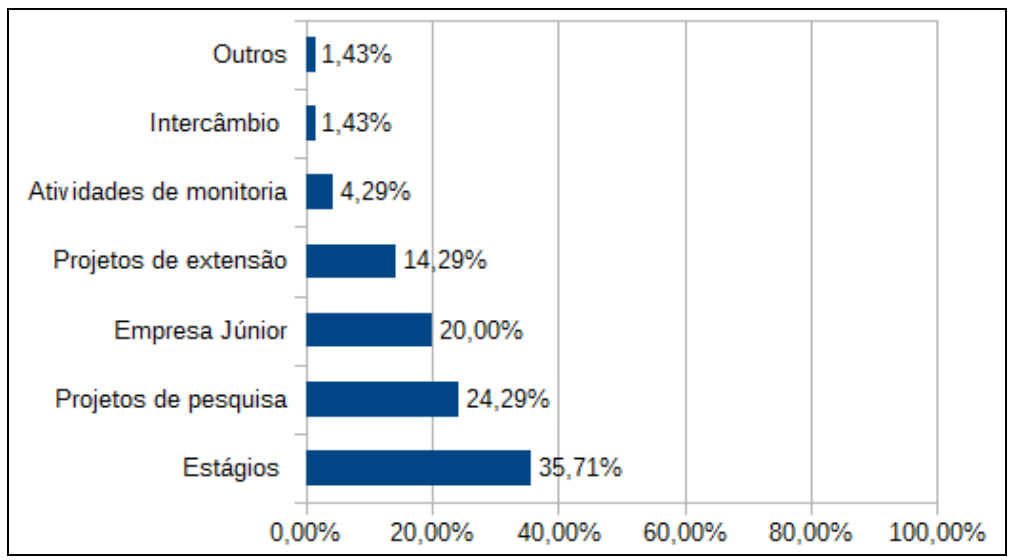

Fonte: elaborado pelas autoras.

Essas atividades possibilitam agregar uma melhor qualidade à formação recebida pelos estudantes, pois auxiliam no alinhamento da teoria com a prática, além do que têm uma importância fundamental não apenas no desempenho acadêmico, mas nas escolhas futuras dos egressos, pois permitem a vivência de experiências diferenciadas no contexto acadêmico que poderão direcioná-los futuramente para áreas que eles encontrem maior afinidade, seja no que se refere à continuidade da formação acadêmica ou à inserção e atuação profissional.

A continuidade da formação também é uma prerrogativa que se relaciona à inserção profissional, pois ao mesmo tempo em que alguns a buscam pela dificuldade de ingressar no mercado de trabalho logo após a formatura, outros almejam alcançar posições melhores no mercado de trabalho ou até prosseguir na carreira acadêmica (MATTOS, 2011). Os dados do gráfico 2 revelam que nesse quesito, dos 70 egressos, 44 (62,9\%) ainda não aderiram à realização de cursos de pós-graduação, mas há uma proporção considerável que buscou realizar cursos de especialização $(32,85 \%)$ e uma minoria $(4,28)$ que ingressaram em programas de mestrado. 
Gráfico 2 Continuidade dos estudos após a graduação

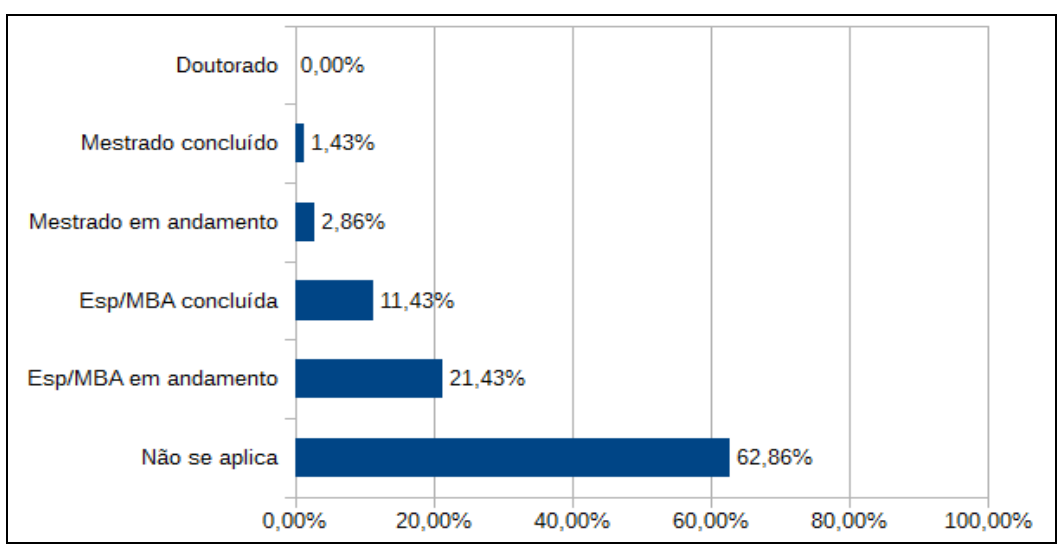

Fonte: elaborado pelas autoras.

Entre os fatores que podem ter influenciado nessa decisão estão as condições laborais e financeiras dos egressos, bem como o curto espaço de tempo decorrido desde a formatura. Cabe ressaltar que as ofertas de pós-graduação stricto sensu na região são limitadas e pagas, assim como a maioria dos cursos de especialização na área de administração, disponibilizados apenas por universidades privadas, mediante a cobrança de mensalidades. Entra em evidencia neste caso uma contraposição à percepção de Mattos (2011), pois a inserção profissional precede a continuidade dos estudos no rol de prioridades dos egressos, sendo na maioria dos casos condição imprescindível para o avanço da formação acadêmica.

Quanto ao perfil profissional, 47 (67,1\%) egressos relataram estarem trabalhando em empregos formais, com carteira assinada, 13 são servidores públicos $(18,6 \%)$, quatro $(5,7 \%)$ estão na informalidade, três $(4,3 \%)$ são empresários e dois $(2,9 \%)$ se dedicam a outras atividades. Apenas um egresso informou estar desempregado.

Os egressos foram questionados sobre a renda que obtinham antes de ingressarem no curso e a renda que possuem atualmente. Com base nestas informações foi possível mensurar a evolução da renda dos egressos antes e depois de terem se formado no curso de Administração. Esse comparativo sobre a renda antes do ingresso no curso de administração e a renda do egresso após a formatura evidencia uma evolução positiva, conforme apontam as informações explicitadas na tabela 1:

Os indivíduos que inicialmente não possuíam renda ou recebiam até um saláriomínimo, que consistiam em um número representativo de $64,2 \%$, obtiveram aumento na remuneração, passando para as faixas subsequentes, sendo que apenas $4,3 \%$ continuam sem renda, (dois que não exercem atividade remunerada e um que se encontra desempregado) e ninguém recebe menos que o salário-mínimo. As faixas entre um e três salários-mínimos e 
entre três e cinco salários-mínimos também mostraram um crescimento significativo de $21,4 \%$ e $31,4 \%$, respectivamente. A faixa entre cinco a sete salários mínimos obteve um aumento menor em comparação com as anteriores, fixado em $2,8 \%$ e a faixa entre sete a 10 salários-mínimos que inicialmente não apresentava nenhum índice alcançou a proporção de $4,3 \%$ dos egressos.

Tabela 1 Comparação da renda antes de ingressar no curso e a atual renda após a formatura

\begin{tabular}{lcccc}
\hline \multirow{2}{*}{ Renda } & \multicolumn{2}{c}{ Antes de ingressar no curso } & \multicolumn{2}{c}{ Depois de formado } \\
\cline { 2 - 5 } & $\mathbf{N}$ & $\mathbf{\%}$ & $\mathbf{N}$ & $\mathbf{\%}$ \\
\hline Nenhuma & 19 & $27,10 \%$ & 3 & $4,30 \%$ \\
Até 1 salário-mínimo & 26 & $37,10 \%$ & 0 & $0,00 \%$ \\
De 1 a 3 salários-mínimos & 21 & $30,00 \%$ & 36 & $51,40 \%$ \\
De 3 a 5 salários-mínimos & 2 & $2,90 \%$ & 24 & $34,30 \%$ \\
De 5 a 7 salários-mínimos & 2 & $2,90 \%$ & 4 & $5,70 \%$ \\
De 7 a 10 salários-mínimos & 0 & $0,00 \%$ & 3 & $4,30 \%$ \\
\hline Total & $\mathbf{7 0}$ & $\mathbf{1 0 0 , 0 0 \%}$ & $\mathbf{7 0}$ & $\mathbf{1 0 0 , 0 0 \%}$ \\
\hline
\end{tabular}

Fonte: Elaborada pelas autoras.

Os motivos que podem justificar essa evolução estão relacionados especialmente ao ingresso no mercado de trabalho durante e após a realização do curso. A idade dos egressos também exerce influência nesse processo, pois muitos jovens pertencentes às camadas populares procuram ingressar no mercado de trabalho assim que atingem a maioridade, mas encontram dificuldades em obter boas colocações no início da carreira, de modo que esse quesito requer novas avaliações no decorrer do tempo para uma avaliação mais aprofundada.

Portanto, a evolução da renda neste estágio pode ser atribuída à realização do curso à medida que alguns outros fatores, tais como o tempo necessário para obter um trabalho na área de administração e a mensuração dos índices de diplomados que já trabalhavam na área de formação ao concluir o curso, ou que não atuam neste campo, passam a ser avaliados.

Os egressos que já atuavam na área de formação predominam com 45 respondentes (64,3\%). A prática de atividades extraclasse, como os estágios, podem ter contribuído para tanto, pois figuram como uma porta de entrada para o mercado de trabalho. Entre aqueles que procuraram trabalho, oito egressos $(11,4 \%)$ o encontraram no período de até três meses, quatro deles $(5,7 \%)$ ingressaram em até seis meses e sete $(10,0 \%)$ precisaram de mais de seis meses para conseguir um emprego na área, enquanto seis egressos $(8,6 \%)$ ainda permanecem atuando fora da área da administração. Neste quesito, o egresso desempregado levou em consideração seu emprego mais recente. 
Adentrando nas áreas específicas de atuação profissional, a administração geral abarca uma proporção maior dos participantes, correspondente a 41,3\%. Entretanto, é possível presumir que alguns respondentes tenham optado por esta alternativa tendo em vista que não encaixaram suas atividades em nenhuma das outras áreas. A área de finanças obteve uma representação expressiva com $30,2 \%$, seguida de recursos humanos com $7,9 \%$, logística com 6,3\%, materiais e gestão universitária, ambas com 3,2\%. Outros itens como: marketing, produção, controladoria, gestão pública e organização industrial caracterizam 1,6\%, com apenas um egresso em cada área.

As maiores dificuldades encontradas no mercado de trabalho pelos diplomados estão relacionadas à falta de experiência profissional, relatada por $41,4 \%$ dos egressos e a alta concorrência na área almejada, percebida por $44,3 \%$ dos participantes, o que ressalta mais uma vez o papel dos estágios durante a realização do curso como uma possível porta de entrada no mercado de trabalho, uma vez que possibilitam a obtenção de experiência fomentam o relacionamento do estudante com o campo profissional.

Gráfico 3 Dificuldades encontradas no mercado de trabalho depois de formado

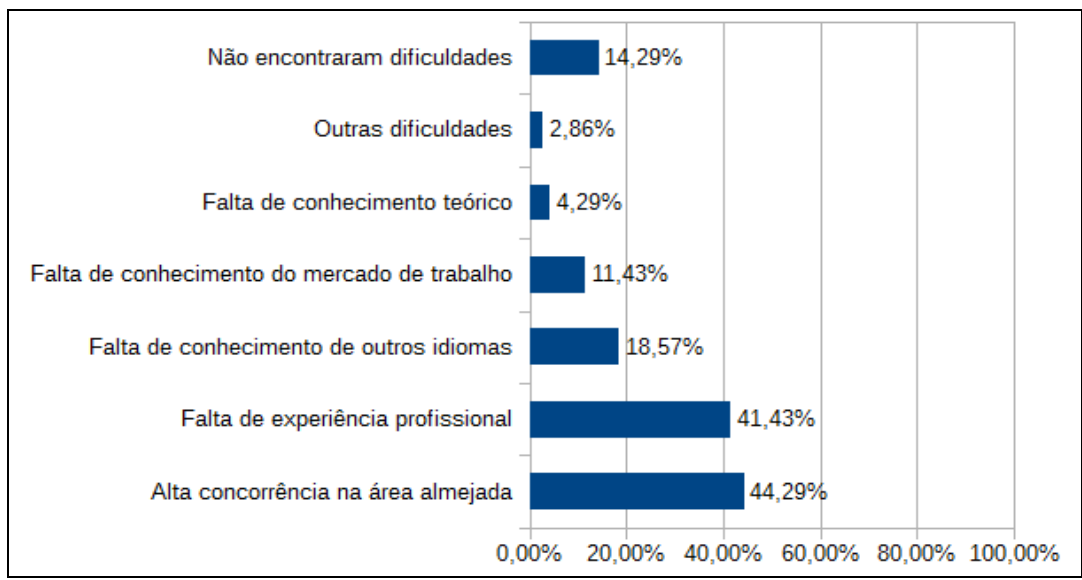

Fonte: Elaborado pelas autoras.

A falta de conhecimento de outros idiomas resultou em uma dificuldade considerável com índice de $18,6 \%$, além da falta de conhecimento em relação ao mercado de trabalho com $11,4 \%$ e falta de conhecimento teórico com 4,3\%. O item "Outras dificuldades" citado na figura 6 e atribuído por $2,86 \%$ dos egressos está atrelado a questões como a crise econômica e o currículo superior ao requerido pela vaga em que se candidatava. Além disso, 14,29\% dos egressos relataram não terem encontrado dificuldades para ingressar no mercado de trabalho. 
Além disso, ao avaliar o impacto que o diploma gerou na carreira dos egressos que já estavam empregados, nota-se que 35 egressos (50\%), ou seja, a metade deles recebeu algum tipo de promoção após terem se formado em administração, ao passo que 21 (30\%) disseram não ter recebido nenhum tipo de ascensão e $20 \%$ não estavam trabalhando no período em que se formaram. Esses dados também estão relacionados à evolução da renda dos egressos associada à realização do curso.

No tocante à avaliação do curso realizado e da universidade, os egressos foram consultados sobre alguns aspectos que perceberam durante e após a sua diplomação e que podem ser úteis para a coordenação do curso e para a gestão do campus. Na avaliação referente aos componentes do curso e da universidade, os respondentes classificaram cada item com a descrição a seguir, sendo que para a análise dessa classificação foram atribuídos pesos em escala de acordo com a referência correspondente a cada descritivo: Muito ruim = peso (-2); Ruim = peso (-1); Regular = peso (1); Bom = peso (2); Muito bom = peso (3). A classificação "Não sei” não teria impacto na avaliação sendo atribuído a ela o valor zero (0).

Assim em uma escala entre (-140) e 210 é considerada negativa a avaliação que na soma dos índices está entre (-140) e (-1), seria considerada regular a avaliação entre um e 70 e positiva a avaliação com pontuação entre 71 e 210 .

A avaliação acerca dos componentes do curso de Administração pode ser explorada para avaliar e até melhorar alguns aspectos relacionados ao curso, caso seja necessário. $\mathrm{Na}$ tabela 2, é possível verificar a classificação dada pelos egressos a cada componente do curso.

Tabela 2 Avaliação dos componentes do curso

\begin{tabular}{lcccccc}
\hline \multicolumn{1}{c}{ Componentes do curso } & $\begin{array}{c}\text { Muito ruim } \\
(-\mathbf{- 2})\end{array}$ & $\begin{array}{c}\text { Ruim } \\
\mathbf{( - 1 )}\end{array}$ & $\begin{array}{c}\text { Regular } \\
(\mathbf{1})\end{array}$ & $\begin{array}{c}\text { Bom } \\
\text { (2) }\end{array}$ & $\begin{array}{c}\text { Muito bom } \\
\text { (3) }\end{array}$ & $\sum$ \\
\hline Bibliografia & 0 & 0 & 9 & $45(90)$ & $16(48)$ & $\mathbf{1 9 2}$ \\
Corpo docente & 0 & $3(-3)$ & 5 & $32(64)$ & $30(90)$ & $\mathbf{1 5 6}$ \\
Didática adotada & 0 & $2(-2)$ & 17 & $40(80)$ & $11(33)$ & $\mathbf{1 2 8}$ \\
Inter-relação entre teoria e prática & $1(-2)$ & $6(-6)$ & 24 & $29(58)$ & $10(30)$ & $\mathbf{1 0 4}$ \\
Grade curricular ofertada & $2(-4)$ & $3(-3)$ & 21 & $38(56)$ & $6(18)$ & $\mathbf{8 8}$ \\
\hline
\end{tabular}

Fonte: Elaborada pelas autoras.

Os componentes avaliados foram a grade curricular ofertada durante a realização do curso que obteve uma avaliação positiva, porém com uma posição baixa na escala entre 71 e 210 pontos, atingindo 88 pontos, seguido da inter-relação entre teoria e prática com uma avaliação também positiva na escala, somando 104 pontos, da didática adotada com um escore de 128 pontos, do corpo docente que alcançou a soma de 156 pontos e da bibliografia 
que obteve a melhor pontuação, aproximando-se do índice máximo com 192 pontos. Cabe destacar que o PPC do curso foi alterado para as turmas posteriores, evidenciando a preocupação da coordenação com relação à grade curricular ofertada.

Após a avaliação do curso foram avaliados os componentes da universidade, visto que ela possui papel fundamental na formação dos discentes do curso de administração. O quesito "Não sei” não foi considerado na pontuação, pois está relacionado ao número de egressos que não utilizaram os serviços ou estruturas da universidade durante o período em que permaneceram no campus e podem estar relacionados a fatores como não terem percebido a necessidade de sua utilização ou simplesmente não tê-las procurado no momento em que precisaram delas, como os laboratórios, por exemplo. Outro fator a ser considerado é que os participantes compreendem os egressos das primeiras turmas formadas pela UFFS e, portanto algumas estruturas ainda não estariam a sua disposição durante grande parte do período, como o restaurante universitário, por exemplo, que iniciou suas atividades em setembro de 2014, quando já haviam alunos formados. Isso reforça a importância de dar continuidade a esse tipo de avaliação no decorrer do tempo para acompanhar a evolução desses componentes.

Na tabela 3 são detalhados os índices atribuídos pelos egressos para a classificação de cada componente avaliado com sua respectiva pontuação:

Tabela 3 Avaliação dos componentes da universidade

\begin{tabular}{|c|c|c|c|c|c|c|c|}
\hline Componentes da universidade & $\begin{array}{l}\text { Muito ruim (- } \\
\text { 2) }\end{array}$ & $\begin{array}{c}\text { Ruim } \\
(-1)\end{array}$ & $\begin{array}{c}\text { Regular } \\
\text { (1) }\end{array}$ & $\begin{array}{c}\text { Bom } \\
(2)\end{array}$ & $\begin{array}{c}\text { Muito bom } \\
\text { (3) }\end{array}$ & $\begin{array}{c}\text { Não sei } \\
(0)\end{array}$ & $\sum$ \\
\hline Biblioteca & 0 & $2(-2)$ & 13 & $34(68)$ & $19(57)$ & $2(0)$ & 136 \\
\hline Salas de aula & 0 & $1(-1)$ & 16 & $32(64)$ & $17(51)$ & $4(0)$ & 130 \\
\hline Estrutura organizacional & $2(-4)$ & $1(-1)$ & 9 & $39(78)$ & $14(42)$ & $5(0)$ & 124 \\
\hline $\begin{array}{l}\text { Programas de assistência } \\
\text { estudantil }\end{array}$ & $1(-2)$ & $1(-1)$ & 8 & $20(40)$ & $24(72)$ & $16(0)$ & 117 \\
\hline Áreas comuns & 0 & $4(-4)$ & 23 & $26(52)$ & $15(45)$ & $2(0)$ & 116 \\
\hline Restaurante Universitário & $1(-2)$ & 0 & 6 & $19(38)$ & $18(54)$ & $26(0)$ & 96 \\
\hline Incentivos à pesquisa & $3(-6)$ & $7(-7)$ & 11 & $26(52)$ & $15(45)$ & $8(0)$ & 95 \\
\hline Incentivos à extensão & $3(-6)$ & $8(-8)$ & 13 & $22(44)$ & $16(48)$ & $8(0)$ & 91 \\
\hline Laboratórios & $5(-10)$ & $6(-6)$ & 15 & $20(40)$ & $7(21)$ & $17(0)$ & 60 \\
\hline Internacionalização & $5(-10)$ & $5(-5)$ & 17 & $16(32)$ & $9(21)$ & $16(0)$ & 55 \\
\hline
\end{tabular}

Fonte: Elaborada pelas autoras.

De acordo com a escala de pontuações, os egressos atribuíram índices que seguem a tendência de regular (1 a 70 pontos) para os quesitos internacionalização com 55 pontos e laboratórios que obteve 60 pontos, os demais itens foram avaliados como positivos com escore entre 91 e 136 pontos na escala de 71 até 210 . As pontuações obtidas por cada um dos 
quesitos avaliados positivamente segue, em ordem crescente: incentivos à extensão (91 pontos); incentivos à pesquisa (95 pontos); restaurante universitário (96 pontos); áreas comuns (116 pontos); programas de assistência estudantil (117 pontos); estrutura organizacional (124 pontos); salas de aula (130 pontos) e a biblioteca foi o espaço melhor avaliado com 136 pontos.

Para a avaliação das contribuições do curso e da universidade para o desenvolvimento do egresso nos aspectos pessoais foram atribuídas as pontuações: Não houve $=(-1)$; Pouca $=$ (1); Razoável $=(2)$, e; Decisiva $=(3)$. Colocando os valores na escala, a pontuação segue a variação entre (-70) e 210. Os indicadores cujo intervalo da escala estiver entre (-70) e (-1) representam uma avaliação expressamente negativa, evidenciando que não houve nenhuma contribuição. A pontuação entre zero e 105, apesar de não ser negativa, também não é desejável, pois equivale à constatação de que o curso e a universidade pouco contribuíram para o desenvolvimento do egresso, não atendendo ao seu objetivo. Os índices cuja soma estiver entre 106 e 175 representam uma contribuição razoável e entre 176 a 210 que a contribuição foi decisiva, considerando a opinião da maioria dos egressos. A tabela 4 apresenta os resultados obtidos para cada indicador:

Tabela 4 Contribuição do curso e da universidade para o desenvolvimento do egresso

\begin{tabular}{|c|c|c|c|c|c|}
\hline Contribuição & Não houve (-1) & Pouca (1) & Razoável (2) & Decisiva (3) & $\sum$ \\
\hline $\begin{array}{l}\text { Do curso para desenvolvimento } \\
\text { pessoal }\end{array}$ & 0 & 0 & $21(42)$ & 49 (147) & 189 \\
\hline $\begin{array}{l}\text { Do curso para desenvolvimento } \\
\text { profissional }\end{array}$ & 0 & 4 & $23(46)$ & 43 (129) & 179 \\
\hline $\begin{array}{l}\text { Da universidade para } \\
\text { desenvolvimento pessoal }\end{array}$ & 0 & 4 & $29(58)$ & 37 (111) & 173 \\
\hline $\begin{array}{l}\text { Da universidade para o } \\
\text { desenvolvimento profissional }\end{array}$ & $1(-1)$ & 5 & $26(52)$ & 38 (114) & 170 \\
\hline
\end{tabular}

Fonte: Elaborada pelas autoras.

A avaliação é considerada positiva quando os indicadores analisados atingiram uma avaliação superior a 106, uma vez que uma contribuição inexpressiva não responde aos investimentos realizados para a manutenção da estrutura do curso e evidencia que os egressos receberam uma formação que não os preparou satisfatoriamente para enfrentar os desafios da vida cotidiana e do mercado de trabalho. Desse modo, observa-se que todos os indicadores apresentados foram avaliados positivamente pelos respondentes, o que pressupõe que o curso de administração e a UFFS estão contribuindo satisfatoriamente para o desenvolvimento pessoal e profissional dos egressos e assim, cumprindo com o seu papel formativo. 
Com base nas competências e habilidades estabelecidas nas Diretrizes Curriculares Nacionais do Curso de Graduação em Administração, os egressos avaliaram as aptidões adquiridas em cada uma das diretrizes por meio das opções: Não apto $=(-1)$; Parcialmente apto $=(1)$ e Plenamente apto $=(2)$. Na análise foi considerada a variação entre os valores $(-$ 70) e 140. A pontuação entre (-70) e zero expressa que a maioria dos egressos não adquiriu as referidas habilidades/competências, entre zero e 105 para os casos em que a maioria dos egressos adquiriu parcialmente as referidas habilidades/competências e entre a pontuação entre 106 e 140 evidencia que a maioria se considera plenamente apto para exercer as habilidades/competências estabelecidas para o curso. Os dados relativos a essa avaliação constam na tabela 5:

Tabela 5 Avaliação das competências e habilidades estabelecidas nas Diretrizes Curriculares Nacionais

\begin{tabular}{|c|c|c|c|c|}
\hline $\begin{array}{l}\text { Avaliação das competências e habilidades estabelecidas nas } \\
\text { Diretrizes Curriculares Nacionais }\end{array}$ & $\begin{array}{c}\text { Não apto } \\
(-1)\end{array}$ & $\begin{array}{l}\text { Parcialmente } \\
\text { apto (1) }\end{array}$ & $\begin{array}{l}\text { Plenamente } \\
\text { apto (2) }\end{array}$ & $\sum$ \\
\hline $\begin{array}{l}\text { Ter iniciativa, criatividade, determinação, vontade política e } \\
\text { administrativa, vontade de aprender, abertura às mudanças e consciência } \\
\text { da qualidade e das implicações éticas do seu exercício profissional. }\end{array}$ & 0 & 13 & $57(114)$ & 127 \\
\hline $\begin{array}{l}\text { Desenvolver capacidade de transferir conhecimentos e experiências para } \\
\text { o ambiente de trabalho e seu campo de atuação, em diferentes modelos } \\
\text { organizacionais, revelando-se profissional adaptável. }\end{array}$ & $2(-2)$ & 21 & $47(94)$ & 113 \\
\hline Desenvolver uma comunicação compatível com o exercício profissional. & 0 & 27 & $43(86)$ & 113 \\
\hline $\begin{array}{l}\text { Reconhecer problemas, elaborar soluções, pensar estrategicamente, a fim } \\
\text { de exercer a tomada de decisão. }\end{array}$ & 0 & 36 & $34(68)$ & 104 \\
\hline $\begin{array}{l}\text { Refletir e atuar criticamente sobre o campo da produção, } \\
\text { compreendendo sua posição e função na estrutura produtiva. }\end{array}$ & $1(-1)$ & 40 & $29(58)$ & 97 \\
\hline $\begin{array}{l}\text { Desenvolver capacidade para elaborar, implementar e consolidar } \\
\text { projetos em organizações. }\end{array}$ & $7(-7)$ & 29 & $34(68)$ & 90 \\
\hline $\begin{array}{l}\text { Desenvolver raciocínio lógico, crítico e analítico para operar com } \\
\text { valores e formulações matemáticas. }\end{array}$ & $7(-7)$ & 33 & $30(60)$ & 86 \\
\hline $\begin{array}{l}\text { Desenvolver capacidade para realizar consultoria em gestão e } \\
\text { administração, pareceres e perícias administrativas, gerenciais, } \\
\text { organizacionais, estratégicos e operacionais. }\end{array}$ & $12(-12)$ & 45 & $13(26)$ & 59 \\
\hline
\end{tabular}

Fonte: Elaborada pelas autoras.

A análise proposta evidenciou que a maioria dos egressos adquiriu as habilidades/competências requeridas pelo curso em nível parcial, uma vez que não houve pontuações inferiores a 35 e um índice de cinco competências/habilidades pontuaram na escala entre a variação compreendida entre 36 e 105, ao passo que houveram três competências que os egressos avaliaram estarem plenamente aptos a aplicarem no campo pessoal e profissional. 
Neste aspecto, nota-se que as competências/habilidades comportamentais e aquelas voltadas à aplicação do conhecimento teórico recebido em sala de aula se sobressaíram na avaliação, enquanto que aquelas relacionadas com a prática profissional ainda precisam ser em certa medida desenvolvidas. Cabe destacar que algumas dessas competências carecem de uma interação maior com o campo profissional para serem adquiridas plenamente, seja pela experiência obtida pelos estágios, ou pela própria atuação no mercado de trabalho.

\section{CONCLUSÃO}

A avaliação dos egressos fornece subsídios para a tomada de decisões estratégicas pelos gestores do curso e da universidade, com vistas à melhoria contínua dos processos pedagógicos, alinhando-os com as necessidades observadas pelo corpo discente, neste caso aqueles que completaram todo o ciclo de formação. As informações coletadas são úteis para melhorar e aprimorar o currículo do curso, o desenvolvimento profissional dos administradores diplomados pela UFFS e para a implantação de políticas de acompanhamento de egressos na universidade.

Os principais aspectos apontados pelos egressos que carecem de atenção pela coordenação do curso e pela gestão do campus estão relacionados ao campo profissional. Esta constatação ficou evidente na avaliação dos componentes do curso, na contribuição do curso e da universidade para o desenvolvimento do egresso, bem como na avaliação das competências/habilidades adquiridas pelos egressos com a formação recebida. Conhecer o perfil e as perspectivas dos egressos auxiliou a compreensão destas percepções, pois a maioria dos egressos buscou a formação acadêmica para ingressar ou melhorar sua colocação no mercado de trabalho, ao passo que uma proporção menor optou pela carreira acadêmica.

O fato de grande parte dos egressos estarem atuando na área de formação antes mesmo de terem recebido o diploma, contribuiu sobremaneira para o desenvolvimento das competências/habilidades profissionais relacionadas ao campo profissional e pode ser explorado pelos gestores do curso para melhorar aspectos como a inter-relação entre teoria e prática, por exemplo.

Quanto aos aspectos relacionados à universidade, os investimentos no campo acadêmico, como internacionalização, laboratórios e projetos de pesquisa e extensão foram os mais destacados como prioritários, pois receberam pontuações menores na avaliação do que as áreas estruturais. Essas áreas apresentam-se como uma frente importante na composição da 
agenda da gestão do campus e devem constar também nas pautas de reivindicações da gestão do curso, uma vez que estas atividades extracurriculares foram realizadas por grande parte dos egressos e determinaram em grande medida suas escolhas futuras. Nesse sentido, incluem-se também os investimentos em pós-graduação, para impulsionar a educação continuada dos egressos, prolongando e aprofundando os vínculos destes com a universidade.

Como sugestão de continuidade desta abordagem no âmbito da avaliação do curso de administração da UFFS - Campus Chapecó/SC cabe uma investigação acerca do perfil dos alunos que evadem do curso e os motivos que os motivam a não concluir o curso, o que possibilitará novas tomadas de decisões para a melhoria dos índices comparativos entre o número de ingressantes e egressos. A realização de estudos longitudinais com os egressos também é importante para mensurar o impacto das ações adotadas pela gestão do curso e da universidade após a formação das primeiras turmas para suplantar as limitações ora encontradas.

\section{REFERÊNCIAS}

BARRETO, A. S. A mulher no ensino superior: distribuição e representatividade. Cadernos do GEA, n. 6, jul./dez. 2014.

BRASIL. Lei ${ }^{\circ} 12.029$ de 15 de setembro de 2009. Dispõe sobre a criação da Universidade Federal da Fronteira Sul - UFFS e dá outras providências. Disponível em: $<$ http://www2.camara.leg.br/legin/fed/lei/2009/lei-12029-15-setembro-2009-591206normaatualizada-pl.html> Acesso em: 15 fev. 2017.

CABRAL, T. L. O. A gestão do relacionamento com egressos: uma proposta de diretrizes para o programa de pós-graduação em administração da UFSC. 2017. 153 f. Dissertação (Mestrado) - Programa de Pós-graduação em Administração, Universidade Federal de Santa Catarina, Florianópolis, 2017.

CNE. Resolução $\mathbf{n}^{\circ} \mathbf{1}$, de 2 de fevereiro de 2004. Institui as Diretrizes Curriculares Nacionais do Curso de Graduação em Administração, Bacharelado, e dá outras providências. Disponível em: <http://portal.mec.gov.br/cne/arquivos/pdf/rces01_04.pdf> Acesso em: 25 mai. 2017.

GERHARDT, T. E. (Org.) SILVEIRA, D. T. (Org.) Métodos de Pesquisa. Porto Alegre: Editora da UFRGS, 2009.

GIL, A. C. Como elaborar projetos de pesquisa. 5. ed. São Paulo: Atlas, 2010.

INEP. Instrumento de Avaliação de Cursos de Graduação - presencial e a distância. (INEP, 2015a). Disponível em: 
<http://download.inep.gov.br/educacao_superior/avaliacao_cursos_graduacao/instrumentos/2 015/instrumento_cursos_graduacao_publicacao_agosto_2015.pdf $>$ Acesso em: 25 mai. 2017.

Política Institucional de Integração e de Avaliação do Egresso na Melhoria da IES. SINAES/INEP, vol. 3. Brasília: (INEP, 2015b).

KOONTZ, H; O'DONNELL, Cyril; WEIHRICH, Heinz. Administração. 14. ed. São Paulo: Pioneira, 1986.

LACOMBE, F; HEILBORN, G. Administração: princípios e tendências. São Paulo: Saraiva, 2003.

LOUSADA, A. C. Z; MARTINS, G. A. Egressos como fonte de informação à gestão dos cursos de Ciências Contábeis. Revista Contabilidade e Finanças. v.16, n. 37, 2005.

MARCONI, M. A; LAKATOS, E. M. Fundamentos de metodologia científica. 7. ed. São Paulo: Atlas, 2010.

MAXIMIANO, A. C. A. Introdução à Administração. 7. ed. São Paulo: Atlas, 2009.

MATTOS, V. B. Pós-graduação em tempos de precarização do trabalho: alongamento da escolaridade e alternativa ao desemprego. São Paulo, Xamã, 2011.

MEHEDFF, N. G. A avaliação da educação e a inserção dos egressos do ensino médio no mercado de trabalho. Brasília: Instituto Nacional de Estudos e Pesquisas Educacionais, 1999.

MIRANDA, C. S. PAZELLO, E. T. LIMA, C. B. Egressos como instrumento de avaliação institucional: uma análise da formação e empregabilidade dos egressos da FEA-RP/USP. Revista GUAL, Florianópolis, v. 8, n. 1, p. 298-321, jan. 2015.

MURINI, L. T; FREO, A. A; MADRUGA, L. R. R. G. Mercado de trabalho: a visão dos acadêmicos de administração da UFSM e UNIFRA. VI Colóquio Internacional sobre gestão universitária na América do Sul, Blumenau, 2006.

PINTO, V. R. R; DIVO JUNIOR, M. M. Uma abordagem histórica sobre o ensino da Administração no Brasil. Revista Pensamento Contemporâneo em Administração, [s.l.], v. 6, n. 4, p.1-28, out./dez. 2012.

QUEIROZ, T. P. O bom filho a casa sempre torna: análise do relacionamento entre a Universidade Federal de Minas Gerais e seus egressos por meio da informação. Dissertação de mestrado, Escola de Ciência da Informação, UFMG, 2014.

SILVA, J. M; BEZERRA, R. O. Sistema de Acompanhamento dos Egressos Aplicado na Universidade Federal de Santa Catarina. Revista GUAL, Florianópolis, v. 8, n. 3, p. 1-15, setembro 2015.

SILVESTRE, António Lúis. Análise de Dados e Estatística Descritiva. Portugual: Escolar, 2007. 352 p. 
SIMON, L.W; SILVA, C. C; PACHECO, A. S. V; TOSTA, K. C. B. T. A UFFS como espaço de desenvolvimento, transformação social e preservação da identidade regional. XVI Colóquio internacional de gestão universitária - CIGU. Arequipa, Peru, 2016.

SOBRAL, F; PECI, A. Administração: teoria e prática no contexto brasileiro. São Paulo: Pearson Prentice Hall, 2008.

TEIXEIRA, G. C. S; MACCARI, E. A. Proposição de um plano de ações estratégicas para associações de alunos egressos baseado em benchmarking. In: XIV Colóquio Internacional de Gestão Universitária - CIGU. Florianópolis, 2014.

UFFS. Universidade Federal da Fronteira Sul - Campus Chapecó. Disponível em: $<$ https://www.uffs.edu.br/campi/chapeco>. Acesso em: 22 mai. 2017.

VERGARA, S. C. Métodos de coleta de dados no campo. São Paulo: Atlas, 2009.

YIN, R. K. Estudo de caso: planejamento e métodos. trad. Daniel Grassi, 2.ed. Porto Alegre: Bookman, 2001.

ZANELLA, L. C. H. Metodologia de pesquisa. Florianópolis: SEaD/UFSC, 2006. 